\title{
Diversification of the phaseoloid legumes: effects of climate change, range expansion and habit shift
}

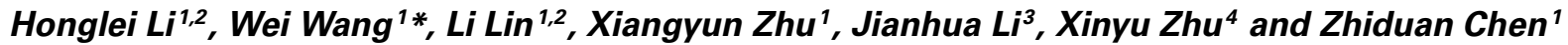 \\ ' State Key Laboratory of Systematic and Evolutionary Botany, Institute of Botany, Chinese Academy of Sciences, Beijing, China \\ 2 Graduate School of Chinese Academy of Sciences, Beijing, China \\ ${ }^{3}$ Biology Department, Hope College, Holland, MI, USA \\ ${ }^{4}$ School of Life Sciences, Nantong University, Nantong, China
}

\author{
Edited by: \\ Xin Wang, Chinese Academy of \\ Sciences, China

\section{Reviewed by:} \\ Yang Liu, University of Connecticut, \\ USA \\ Guo-Qiang Zhang, The Orchid \\ Conservation and Research Center \\ of Shenzhen, China

\section{*Correspondence:} \\ Wei Wang, State Key Laboratory of \\ Systematic and Evolutionary Botany, \\ Institute of Botany, Chinese \\ Academy of Sciences, \\ 20 Nanxincun, Xiangshan, \\ Beijing 100093, China \\ e-mail: wangwei1127@ibcas.ac.cn
}

Understanding which factors have driven the evolutionary success of a group is a fundamental question in biology. Angiosperms are the most successful group in plants and have radiated and adapted to various habitats. Among angiosperms, legumes are a good example for such successful radiation and adaptation. We here investigated how the interplay of past climate changes, geographical expansion and habit shifts has promoted diversification of the phaseoloid legumes, one of the largest clades in the Leguminosae. Using a comprehensive genus-level phylogeny from three plastid markers, we estimate divergence times, infer habit shifts, test the phylogenetic and temporal diversification heterogeneity, and reconstruct ancestral biogeographical ranges. We found that the phaseoloid lineages underwent twice dramatic accumulation. During the Late Oligocene, at least six woody clades rapidly diverged, perhaps in response to the Late Oligocene warming and aridity, and a result of rapidly exploiting new ecological opportunities in Asia, Africa and Australia. The most speciose lineage is herbaceous and began to rapidly diversify since the Early Miocene, which was likely ascribed to arid climates, along with the expansion of seasonally dry tropical forests in Africa, Asia, and America. The phaseoloid group provides an excellent case supporting the idea that the interplay of ecological opportunities and key innovations drives the evolutionary success.

Keywords: aridification, biogeography, dispersal, diversification rate, habit shift, Leguminosae, molecular dating

\section{INTRODUCTION}

Species diversity of different lineages inhabiting the Earth is strikingly heterogeneous. The evolutionary success is responsible for those speciose lineages, but discerning what forces have driven the evolutionary success is a major challenge in evolutionary biology (Schluter, 2000). Recently, ecological opportunity and/or key innovation have been considered as a cause of high diversification rates in many groups (e.g., Yoder et al., 2010; Duputié et al., 2011; Claramunt et al., 2012; Erkens et al., 2012). However, little is known about how ecological opportunity and key innovation have interplayed to promote diversification of a group.

The origin and diversification of angiosperms since the Mesozoic are the great events in the plant kingdom. Angiosperms now include about 300,000 species, have taken various ecological habitats on the Earth, and supplied most raw materials for the well-being of human beings. The family Leguminosae is especially outstanding in this term. The phaseoloid legumes represent one of the largest clades in Leguminosae and consist of 114 genera with $c a .2000$ species (Table S1; Lewis et al., 2005). This clade contains many economically important species, such as soybean (Glycine max), common bean (Phaseolus vulgaris), cowpea (Vigna unguiculata), pigeonpea (Cajanus cajan), horse gram (Macrotyloma uniflorum), siratro (Macroptilium atropurpureum), and coral tree (Erythrina spp.) (Bruneau and Doyle, 1990). Molecular phylogenetic studies have contributed greatly to the delimitation of the clade (Lavin et al., 1998; Hu et al., 2000; Lee and Hymowitz, 2001; Doyle et al., 2003; Wojciechowski et al., 2004; Lewis et al., 2005; Stefanović et al., 2009). Now, the phaseoloid legumes contain four subtribes of Phaseoleae, viz. Phaseolinae, Glycininae, Cajaninae, and Kennediinae, and Psoraleeae and Desmodieae (Lewis et al., 2005; Stefanović et al., 2009). The aforementioned phylogenetic analyses of the clade usually sampled less than $40 \%$ of the generic diversity in the group; thus, to understand the evolutionary dynamics responsible for its current diversity we need a well-resolved phylogeny of the phaseoloid genera with more comprehensive taxon sampling.

Based on an analysis of matK sequences with 13 fossil calibration points, Lavin et al. (2005) suggest that the phaseoloid legumes became differentiated in the Oligocene (24.2-32.1 Ma). Since the Oligocene, global climate has undergone marked changes (Zachos et al., 2001; Wade and Pälike, 2004; Pälike et al., 2006), which may have impacted speciation of many organisms. Egan and Crandall (2008) assume that the recent rapid radiation of Psoraleeae of the phaseoloid legumes may be due to global climate change during the Pleistocene. The phaseoloid legumes possess both woody and herbaceous habits and are primarily distributed in tropical and temperate forests or grasslands (Table S1; Sprent, 2007). The habit shifts have been suggested being responsible for the diversification of some angiosperm lineages (Tiffney and Mazer, 1995; Verdú, 2002; Jabbour and Renner, 
2012). Nevertheless, it remains puzzling and unexplored how evolution of habits fostered diversification in the phaseoloid legumes and how ecological forces have been regulating cladogenesis in different geographical areas.

In this study, we first reconstruct a genus-level phylogeny for the phaseoloid legumes using three plastid loci with a more extensive generic sampling than in any previous studies. In the improved phylogenetic framework, we then explore how the interplay of past climate changes, geographical expansion and habit shifts may have triggered diversification of the phaseoloid legumes.

\section{MATERIALS AND METHODS TAXON SAMPLING}

We sampled 85 species from 82 of the 115 genera of the phaseoloid legumes. Our worldwide taxon sampling scheme covered all tribes and subtribes of Lewis et al. (2005) and major clades of Stefanović et al. (2009) in the phaseoloid legumes. Our outgroups included thirteen species, representing the other three subtribes of Phaseoleae, Diocleinae (four species), Clitoriinae (two species), and Ophrestiinae (one species), which are excluded from the phaseoloid legumes; Millettieae (five species) and Abreae (one species), following the results of Wojciechowski et al. (2004). Voucher information and GenBank accession numbers are listed in Table S2.

\section{LABORATORY PROTOCOLS}

Three chloroplast markers were used in this study: $r b c L, \operatorname{trnL}-F$ region ( $\operatorname{trnL}$ intron, and $\operatorname{trnL}$ [UAA] $3^{\prime}$ exon-trnF [GAA] intergenic spacer), and $\operatorname{trn} K / \operatorname{mat} K$ region (including most of the $3^{\prime}$ flanking trnK intron and the entire matK gene).

Genomic DNA was isolated from silica-gel-dried materials using a Plant Genomic DNA Kit (Beijing Biomed Co., LTD, BJ, China) or from herbarium samples following a modified CTAB procedure (Doyle and Doyle, 1987). Three DNA regions were amplified with the polymerase chain reaction (PCR). The primers used in this study are listed in Table S3. PCR amplifications were performed using $2 \times$ Taq PCR MasterMix (Beijing Biomed Co., LTD) in $25-\mu \mathrm{L}$ reactions with the following thermocycler program: $2 \mathrm{~min}$ at $95^{\circ} \mathrm{C}$ for denaturation, then 35 cycles of $30 \mathrm{~s}$ at $95^{\circ} \mathrm{C}, 30-60 \mathrm{~s}$ at $53-57^{\circ} \mathrm{C}$ for annealing, $2 \mathrm{~min} 30 \mathrm{~s}$ at $72^{\circ} \mathrm{C}$ for primer extension, and a 10 -min incubation at $72^{\circ} \mathrm{C}$ following the cycles. The PCR products were purified using a GFX ${ }^{\mathrm{TM}}$ PCR DNA and Gel Band Purification Kit (Amersham Pharmacia Biotech, Piscataway, NJ, USA) and then directly sequenced. Sequencing reactions were conducted using an ABI Prism BigDye Terminator Cycle Sequencing Kit (Applied Biosystems, ABI, BJ, China). Sequences were analyzed using ABI $3730 \times 1$ DNA Analysis Systems and following the manufacturer's protocols.

\section{PHYLOGENY AND DIVERGENCE TIME ESTIMATES}

Sequence alignments were done using CLUSTAL X v2.0 (Larkin et al., 2007) and manually adjusted with BioEdit v5.0.9 (Hall, 1999). All alignments are available upon request from the corresponding author. We used the Bayesian relaxed clock methodology as implemented in BEAST v1.7.5 (Drummond et al., 2012) to generate a dated phylogeny of the phaseoloid legumes. The
GTR $+\mathrm{I}+\Gamma$ model was selected as the best-fit model for each plastid region determined by ModelTest v3.7 (Posada and Crandall, 1998). Base frequencies were estimated. Clock rate was estimated under an uncorrelated relaxed-clock log-normal (UCLN) model. A Yule speciation model was used as a prior on the tree.

Some fruit and leaf fossils of Pueraria of the phaseoloids from the Middle Miocene of middle latitudes in Asia have been described (Wang et al., 2010, and references therein), but we did not use them as calibration points because Pueraria is not monophyletic (Lee and Hymowitz, 2001; Stefanović et al., 2009; this study). Employing 13 fossil age constraints imposed on the matK phylogeny, Lavin et al. (2005) provide a credible age framework for Leguminosae. Following the results of Lavin et al. (2005), we selected six calibration points: (1) a $45.2 \mathrm{Ma}$ constraint on the root age (node 1); (2) the split between Platycyamus regnellii and the phaseoloid legumes (node 2) was set to $39.7 \mathrm{Ma}$; (3) an age of $27.8 \mathrm{Ma}$ to constrain the crown group age of the phaseoloid legumes (node 3 ); (4) the crown group age of Desmodieae (node 4) was set to 14.2 Ma; (5) the crown group age of clade VIII (node 5, Figure S1) was set to $19.2 \mathrm{Ma}$; and (6) an age of 6.3 Ma for the crown group age of tribe Psoraleeae (node 6). A normal distribution was used for all six calibration points. The standard deviation was set to contain the lower and higher boundaries of the 95\% highest posterior density values. MCMC searches were run for 100,000,000 generations, sampled every 1000 generations. Tracer v1.5 was used to monitor appropriate burn-in and the adequate effective sample sizes of the posterior distribution $(>200)$. The maximum clade credibility tree was computed by TreeAnnotator v1.7.5 in BEAST software package (Drummond et al., 2012). BEAST analyses were performed in the CIPRES Web Portal 3.1 (Miller et al., 2010).

\section{HABIT EVOLUTION}

The reconstruction of habit evolution in the phaseoloid legumes were carried out using the parsimony method with Mesquite v2.74 (Maddison and Maddison, 2009). The maximum clade credibility tree obtained from BEAST was used in the analysis. Two habit states were scored, herbaceous (including herbs and herbaceous climbing vines) vs. woody (including trees, woody climbers, and shrubs), based on the literature (Table S2).

\section{DIVERSIFICATION ANALYSES}

To visualize the temporal variation in diversification rates, semilogarithmic lineage-through-time (LTT) plots were constructed in the R package APE v2.5-1 (Paradis et al., 2004). To evaluate $95 \%$ credibility interval of the empirical LTT curve, 1000 ultrametric trees randomly sampled from the converged BEAST trees were also used to calculate semilogarithmic LTT plots.

To detect rapid shifts in diversification rates at any specified time, the RC statistic was calculated with the R package GEIGER v1.3-1 (Harmon et al., 2008). Lineages with more or fewer descendents than expected under the constant rate model were hypothesized as a diversification rate shift. Species diversity for the phaseoloid legumes was estimated from the number of species in each genus; missing genera were assigned to corresponding clades based on previous studies (Table S1). Net diversification 


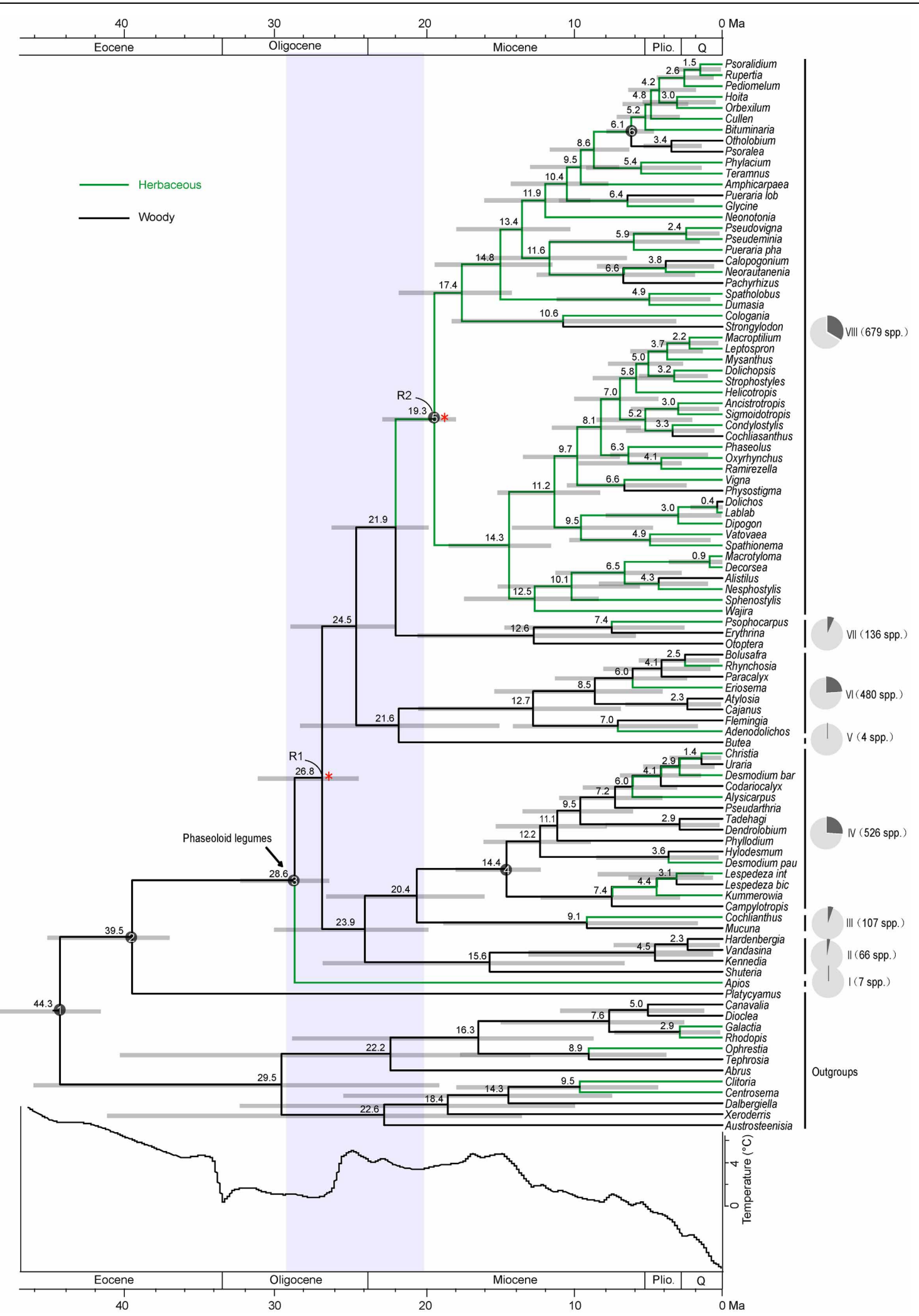

FIGURE 1 | Combined chronogram and habit shift analysis of the phaseoloid legumes. Numbers above branches are divergence times estimated using BEAST. Gray bars show $95 \%$ credibility interval. White numbered nodes represents the calibration node. Red asterisks indicate the nodes (R1, R2) with significant rate increases. Shaded area at the base of the tree highlights initial diversification event. Pie charts represent the proportion of extant phaseoloid species in each clade. The depiction of sea-surface temperature changes is modified from Zachos et al. (2001). 


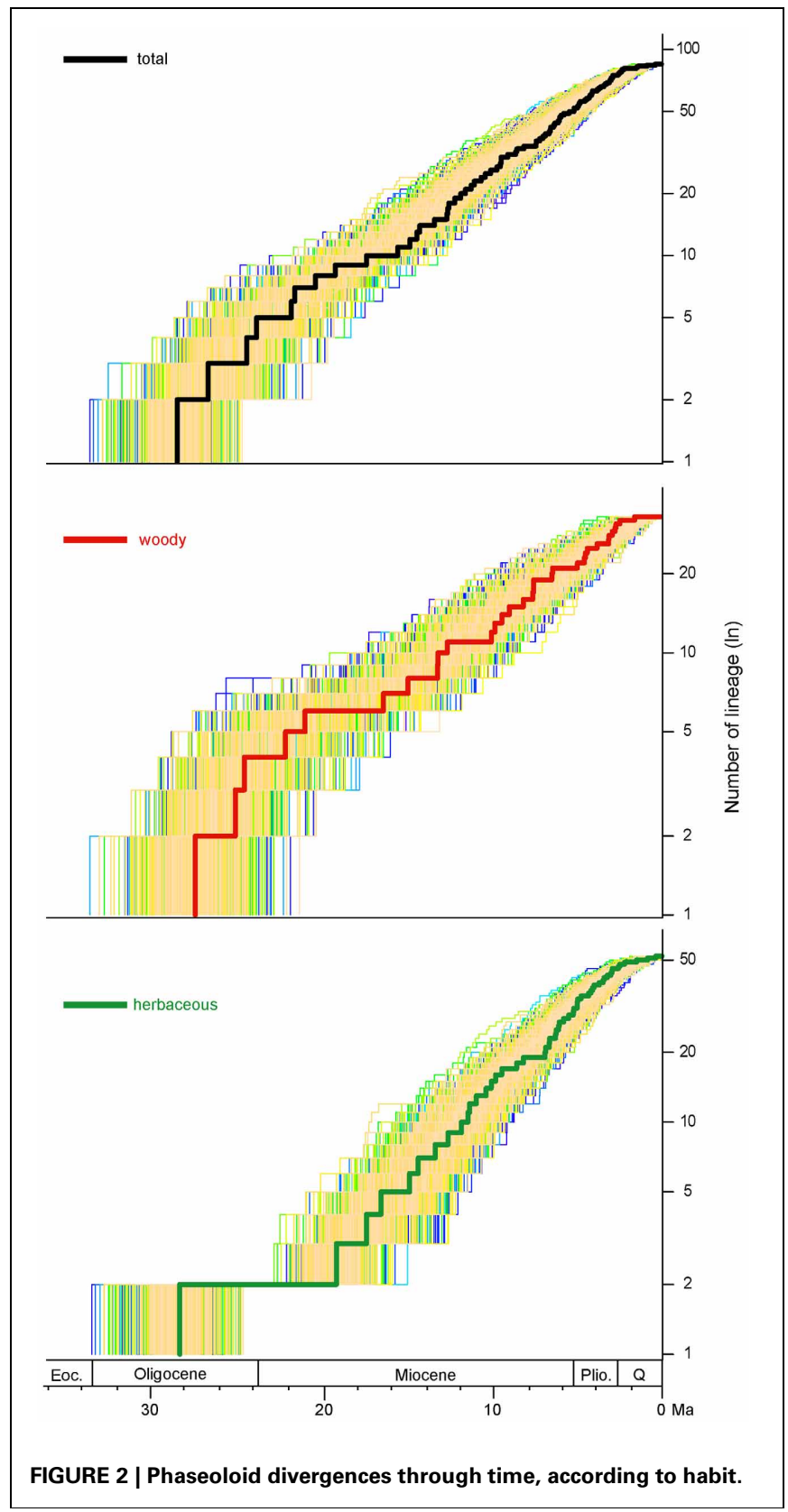

rates $(r)$ for the phaseoloid legumes, nodes R1 and R2 were calculated by using BEAST chronogram under two extremes of the relative extinction rate $(\varepsilon=0$ and 0.9$)$ following the wholeclade method (Magallón and Sanderson, 2001). Calculations were performed using the GEIGER v1.3-1 (Harmon et al., 2008).

\section{BIOGEOGRAPHICAL ANALYSES}

To reconstruct the possible ancestral ranges of the phaseoloid legumes, we conducted a Bayes-DIVA analysis (Nylander et al., 2008) using the software package RASP (Yu et al., 2011). BayesDIVA method can minimize the phylogenetic uncertainties by utilizing the posterior distribution of trees resulting from a BEAST analysis and generating credibility support values for
Table 1 | Relative cladogenesis (RC) test of the phaseoloid legumes. Nodes with diversification rate shift are shown on Figure 1.

\begin{tabular}{llll}
\hline Nodes & Number of ancestor $^{*}$ & Maximum descendents $^{\dagger}$ & $\boldsymbol{P}^{\text {-value }}{ }^{\ddagger}$ \\
\hline R1 & 2 & 84 & 0.024 \\
R2 & 8 & 51 & 0.010 \\
\hline
\end{tabular}

${ }^{*}$ Number of lineages alive before that node on Figure 1.

${ }^{\dagger}$ Maximum number of descendents that node has at the present day based on Figure 1

FThe probability that node had at least maximum descendents under the null hypothesis of a birth-death process.

alternative phylogenetic relationships (Nylander et al., 2008; Yu et al., 2011). We randomly sampled 1000 trees from the BEAST output as a "trees file" and used the maximum clade credibility (MCC) tree as a final representative tree. Biogeographical analyses were conducted on continental spatial scale at generic level, because the aim was to predicate the ancestral areas of nodes deeper down into the tree other than the ancestral areas of individual genera. Six geographic regions were coded: A, Asia; B, Africa; C, Europe; D, Australia; E, South America; F, North America (including Central America and Caribbean). Ancestral areas were reconstructed with the "maxareas" constrained to 3 because 73 of the 82 genera occur in fewer than three areas.

\section{RESULTS}

\section{PHYLOGENY AND DIVERGENCE TIMES}

The maximum clade credibility tree generated by BEAST analyses is well-resolved (Figure S1). Within the phaseoloid legumes, eight major clades were recognized, and the Apios is the earliestdiverging lineage $(P P=0.97)$. Psoraleeae and Desmodieae are strongly supported as monophyletic, both of which are imbedded within Phaseoleae.

Molecular dating shows a stem age for the phaseoloid legumes of $39.5 \mathrm{Ma}$ (35.7-43.2 Ma 95\% highest posterior density, HPD) (Figure 1). The earliest diverged Apios lineage (clade I) separated with the remaining phaseoloids at $28.6 \mathrm{Ma}$ (HPD: 25.8-31.2 Ma). The remaining phaseoloid splits into other seven clades (clade II to VII) between 26.8 and $20.4 \mathrm{Ma}$. The most recent common ancestor (MRCA) of Pueraria phaseoloides and Pueraria lobata emerged at ca. 13.4 Ma (HPD: 9.9-17.0 Ma). The Psoraleeae crown age is estimated at $6.1 \mathrm{Ma}(\mathrm{HPD}: 4.8-7.7 \mathrm{Ma}$ ).

\section{HABIT EVOLUTION}

Results of ancestral habit state reconstruction are shown in Figure 1. The ancestral state of growth habit in the phaseoloid legumes is woody. Within the eight early diverged clades, six are woody (clade II-VII), while clade I and clade VIII are herbaceous. The herbaceous growth habit has evolved at least ten times within the phaseoloids. Importantly, clade VIII is the largest herbaceous lineage with some derived woody species, taking up ca. Thirty percentage species of the phaseoloid legumes.

\section{DIVERSIFICATION RATES}

The semilogarithmic lineage-through-time (LTT) plots for taxa of whole phaseoloid legumes, woody clades (clade II-VII) and 
Table 2 | Net diversification rates $(r)$ calculated for the phaseoloid legumes, nodes R1 and R2.

\begin{tabular}{|c|c|c|c|c|c|c|}
\hline Clades & Stem group mean age (95\%HPD) & No. species & \multicolumn{4}{|c|}{$r$} \\
\hline R1 & $28.6(25.9-31.5)$ & 1998 & 1.05 & $1.05-1.05$ & 1.05 & $1.05-1.05$ \\
\hline R2 & $21.9(18.9-24.9)$ & 679 & 0.30 & $0.26-0.35$ & 0.19 & $0.17-0.22$ \\
\hline
\end{tabular}

herbaceous clades (clade I and VIII) are shown in Figure 2. The whole phaseoloid legumes and woody clades showed a high diversification rate at the early stages (20.4-28.6 Ma). Herbaceous lineages experienced a high diversification rate since the Early Miocene.

The relative cladogenesis (RC) statistic indicated two significant diversification rate shifts at node R1 and R2 within the phaseoloid legumes (Figure 1). The probability of R1 and R2 that had at least maximum descendents under the null hypothesis of a birth-death process are 0.024 and 0.010 separately (Table 1). Net diversification rates of the phaseoloid legumes were estimated as 0.13 (HPD: 0.12-0.15) net speciation events per million years $\left(\mathrm{sp} \mathrm{Myr}^{-1}\right)$ under a high relative extinction rate $(\varepsilon=0.9)$, and $0.19 \mathrm{sp} \mathrm{Myr}^{-1}$ under no extinction $(\varepsilon=0)$. Diversificaiton rates estimated for nodes R1 and R2 are shown in Table 2.

\section{BIOGEOGRAPHICAL RECONSTRUCTION}

The results of ancestral area reconstruction using Bayes-DIVA in RASP is shown in Figure 3. The most recent common ancestor of the phaseoloid legumes is in Asia. Two independent intercontinental dispersal events occurred in the Late Oligocene. The first dispersal is to Africa with the rise of clade V, VI, VII, and VIII. The second dispersal is to Australia giving rise to clade II including Hardenbergia, Vandasina,Kennedia, and Shuteria. In the Miocene, the ancestral range of clade VIII expanded to South and North America following multiple dispersal events.

\section{DISCUSSION}

Our divergence time estimates (Figure 1) suggest a stem age of 39.5 Ma (HPD: 35.7-43.2 Ma) for the phaseoloid legumes and a crown age of 28.6 Ma (HPD: 25.8-31.2 Ma), which are consistent with the estimates of Lavin et al. (2005); Stefanović et al. (2009). Egan and Crandall (2008) estimate the crown age of $6.78 \mathrm{Ma}$ for Psoraleeae, which is in accordance with our result (6.1 Ma; HPD: 4.8-7.7 Ma). Based on our time estimates, the MRCA of Pueraria loata and Pueraria phaseoloides dated back to the Middle Miocene (ca. 13.8 Ma), which coincides with the oldest fruit and foliage fossil records of Pueraria (Wang et al., 2010, and References therein). These suggest that our divergence date estimates for the phaseoloid legumes are reliable.

The phaseoloid legumes originated in the Late Eocene, but the group became differentiated in the Late Oligocene of Asia, and a dramatic accumulation of the phaseoloid lineages immediately occurred during the Late Oligocene and Early Miocene, with two dispersal events, from Asia to Africa and Australia. The rapid divergence time post-dates a period of a drastic global cooling resulting, in part, from the development of permanent continental ice-sheets in Antarctica (Zachos et al., 2001). This cooling induced a drier climate on a global scale (Zachos et al., 2001). The Himalaya-Tibetan plateau experienced rapid uplift at $\sim 40 \mathrm{Ma}$ (Zhang et al., 2006). These events fragmented the panOld World Eocene forest ecosystems and subsequently opened many new niches (Raup and Sepkoski, 1986; Prothero, 1994; Crisp and Cook, 2009). The RC test found that node R1 originated at $28.54 \mathrm{Ma}$ (HPD: $25.76-31.23 \mathrm{Ma}$ ) had a significant rate increase (Figure 1; Table 1). Net diversification rate of node R1 is obviously higher than that of the whole phaseoloid legumes (Table 2). Considering the inferred credibility intervals of the estimated times of divergence, the eight early-divergent clades (I-VIII) seem to have occurred within an 8-million-year time window (28.6-20.4 Ma), which is a period of global warming emerged (Mosbrugger, 2005). Among the eight early-divergent clades, at least six is woody (Figure 1). Recent studies have indicated that shrubs and lianas can take advantage of some ecological opportunities and accordingly are regarded as early successional pioneer species (Shaver et al., 1997; Sturm et al., 2005; Tape et al., 2006; Bunn et al., 2007; Hallinger et al., 2010; Hallinger and Wilmking, 2011). Furthermore, the vigor and recruitment of shrubs and lianas can be enhanced by warming climate (Lantz et al., 2009; Forbes et al., 2010). Most of species in the six early-diverging woody clades are (sub)shrubs or lianas (Figure 1; Table S1). Four genera in woody phaseoloid clades, Erythrina (clade VII), Flemingia (clade VI), Cajanus (clade VI), and Lespedeza (clade IV), have been listed as the inclusion of invasive alien species (Rejmánek and Richardson, 2013). Even though our sampling is incomplete, the available morphological, polynological and molecular evidence suggests that species missing from our study would probably not fall within the stems of these woody clades (Table S1). Thus, our finding suggests that the early rapid diversification of the phaseoloid legumes was driven by ecological opportunities created by the emergence of new niches and range expansion, and the Late Oligocene global warming.

LTT plots indicate that the dramatic accumulation of the herbaceous phaseoloid lineages (clade VIII) occurred since the Early Miocene (Figure 2). The RC test found the other shift of diversification rates within the haseoloid legumes, node R2 (clade VIII), whose net diversification rate is higher than that of the whole phaseoloid legumes (Table 2). Clade VIII is herbaceous and contains about 52 genera and 679 species, greatly contributing to phaseoloid diversity (Figure 1). Our biogeographical reconstruction suggests that the MRCA of clade VIII is in Africa and subsequently multiple independent migrations from Africa to Asia, North America, and South America occurred (Figure 3). 


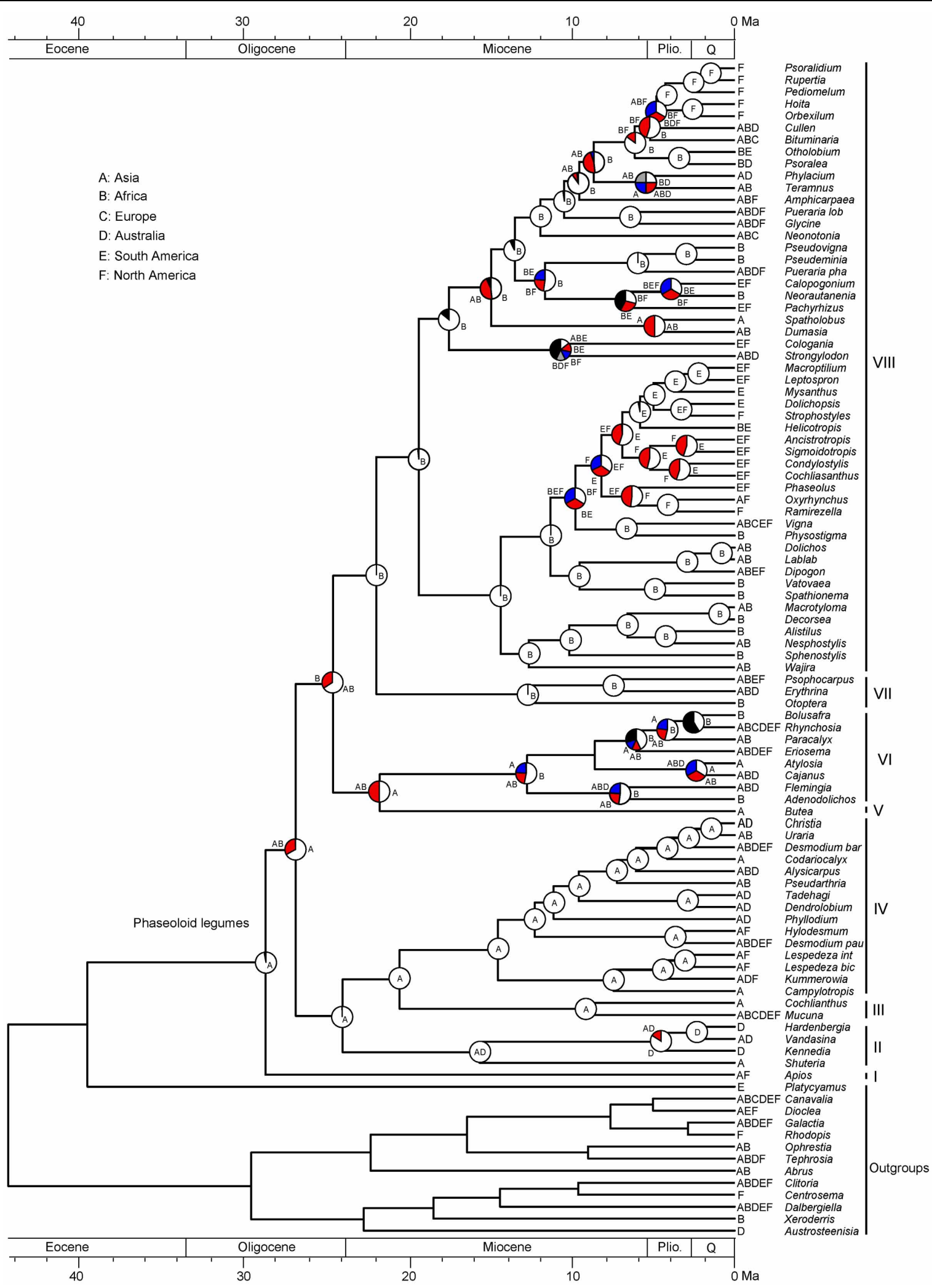

FIGURE 3 | Biogeographical reconstruction of the phaseoloid legumes. The pie charts show the relative probabilities of alternative ancestral distributions obtained by Bayes-DIVA optimizations over the 1000 Bayesian trees (white $>$ red). The first four areas with highest probability are colored according to relative probability in the following order: white $>$ red $>$ blue $>$ gray; and the black portion represents reconstructions with a probability $<0.10$. 
The clade VIII became diversified in the Early Miocene (19.3 Ma; HPD: 17.0-21.6 Ma), which corresponds to the time when the African plate collided with the Eurasian one (ca. 18-17 Ma; Axelrod and Raven, 1978). The geologic event resulted in the closure of the Tethys Sea and brought an end to the moist influence of the latitudinal oceanic circulation system (Axelrod and Raven, 1978; Jacobs, 2004), which, as well as higher global temperatures, may have induced a period of marked aridity in Africa. Moreover, Asia and America also experienced an analogous arid period (Guo et al., 2002; Minnich, 2007; Graham, 2010). The extensive aridity can have promoted the diversification of some groups inhabiting in dry regions, such as Bursera (De-Nova et al., 2012) and the ivesioids of Potentilla (Töpel et al., 2012). De-Nova et al. (2012) postulated that Bursera diversification during the Miocene might be related to the expansion of Mesoamerican seasonally dry tropical forests. The majority of clade VIII species are inhabited in seasonally dry tropical forests (Table 2). Thus, enhanced aridity, as well as the expansion of seasonally dry tropical forests in Africa, Asia, and America, would have promoted the diversification of the herbaceous phaseoloid legumes. Contrary to woody life forms, herbs have a shorter generation time, which will produce higher per-year mutation rates, thus increasing the genetic divergence and increasing speciation rates, consequentially making herbaceous lineages more diverse than woody plants (Eriksson and Bremer, 1992; Dodd et al., 1999; Verdú, 2002). Thus, a habit shift from woody to herbaceous may have acted as a key innovation that resulted in an increased diversification rate of the phaseoloid legumes in the Miocene.

\section{REFERENCES}

Axelrod, D. I., and Raven, P. H. (1978). "Late cretaceous and tertiary vegetation history of Africa," in Biogeography and Ecology of Southern Africa, ed M. J. A. Werger (Netherlands: Springer), 77-130. doi: 10.1007/978-94-0099951-0_5

Bruneau, A., and Doyle, J. J. (1990). A chloroplast DNA inversion as a subtribal character in the Phaseoleae (Leguminosae). Syst. Bot. 15, 378-386. doi: 10.2307/2419351

Bunn, A., Goetz, S. J., Kimball, J. S., and Zhang, K. (2007). Northern high-latitude ecosystems respond to climate change. EOS Trans. Am. Geophys. Union 88, 333-334. doi: 10.1029/2007EO340001

Claramunt, S., Derryberry, E., Brumfield, R., and Remsen, J. (2012). Ecological opportunity and diversification in a continental radiation of birds: climbing adaptations and cladogenesis in the Furnariidae. Am. Nat. 179, 649-666. doi: 10.1086/664998

Crisp, M. D., and Cook, L. G. (2009). Explosive radiation or crypticmass extinction? Interpreting signatures in molecular phylogenies. Evolution 63, 2257-2265. doi: 10.1111/j.1558$5646.2009 .00728 . x$
De-Nova, J. A., Medina, R., Montero, J. C., Weeks, A., Rosell, J. A., Olson, M. E., et al. (2012). Insights into the historical construction of speciesrich Mesoamerican seasonally dry tropical forests: the diversification of Bursera (Burseraceae, Sapindales). New. Phytol. 193, 276-287. doi: 10.1111/j.1469-8137.2011.03909.x

Dodd, M. E., Silvertown, J., and Chase, M. W. (1999). Phylogenetic analysis of trait evolution and species diversity variation among angiosperm families. Evolution 53, 732-744. doi: 10.2307/2640713

Doyle, J. J., and Doyle, J. L. (1987). A rapid DNA isolation procedure for small quantities of fresh leaf tissue. Phytochem. Bull. 19, 11-15.

Doyle, J. J., Doyle, J. L., and Harbison, C. (2003). Chloroplast-expressed glutamine synthetase in Glycine and related Leguminosae: phylogeny gene duplication and ancient polyploidy. Syst. Bot. 28, 567-577.

Drummond, A. J., Suchard, M. A., Xie, D., and Rambaut, A. (2012). Bayesian phylogenetics with BEAUti and the BEAST 1.7. Mol. Biol. Evol. 29, 1969-1973. doi: 10.1093/molbev/mss075

Duputié, A., Salick, J., and McKey, D. (2011). Evolutionary biogeography of Manihot (Euphorbiaceae),

Additionally, some species of the phaseoloid legumes are distributed in grasslands (Table 1; Lewis et al., 2005), which may be associated with the development of grassland ecosystems during the Late Cenozoic (Strömberg, 2011). Nevertheless, a species-level taxon sampling will be needed to examine whether the shift of habitats have also been responsible for diversification of clade VIII.

\section{AUTHOR CONTRIBUTIONS}

Wei Wang and Zhiduan Chen conceived the study. Honglei Li performed the experiments. Honglei Li, Wei Wang, Li Lin, and Xinyu Zhu analyzed the data. Wei Wang, Jianhua Li, Xiangyun Zhu, and Zhiduan Chen contributed reagents/materials/analysis tools. Honglei Li and Wei Wang wrote the paper. Wei Wang, Jianhua Li, and Zhiduan Chen edited the paper.

\section{ACKNOWLEDGMENTS}

We sincerely thank Pamela S. Soltis for carefully reading an early draft of the manuscript. This research was supported by National Basic Research Program of China (No. 2014CB954101), National Natural Science Foundation of China (Nos.31270268, 31270269, and 30990241), and Natural Science Fund for Colleges and Universities in Jiangsu Province (No. 09KJB180006).

\section{SUPPLEMENTARY MATERIAL}

The Supplementary Material for this article can be found online at: http://www.frontiersin.org/journal/10.3389/fpls.2013.00386/ abstract

a rapidly radiating Neotropical genus restricted to dry environments. J. Biogeogr. 38, 1033-1043. doi: $\quad 10.1111 / \mathrm{j} .1365-2699.2011$. 02474.x

Egan, A. N., and Crandall, K. A. (2008). Divergence and diversification in North American Psoraleeae (Fabaceae) due to climate change. BMC Biol. 6:55. doi: 10.1186/17417007-6-55

Eriksson, O., and Bremer, B. (1992). Pollinationsystems dispersalmodes lifeforms and diversification rates in angiosperm families. Evolution 46, 258-266. doi: 10.2307/2409820

Erkens, R. H. J., Chatrou, L. W., and Couvreur, T. L. P. (2012). Radiations and key innovations in an early branching angiosperm lineage (Annonaceae; Magnoliales). Bot. J. Linn. Soc. 169, 117-134. doi: 10.1111/j.1095-8339.2012.01223.x

Forbes, B., Fauria, M. M., and Zetterberg, P. (2010). Russian Arctic warming and greening are closely tracked by tundra shrub willows. Glob. Change Biol. 15, 1-13.

Graham, A. (2010). Late Cretaceous and Cenozoic History of Latin American Vegetation and Terrestrial Environments. StLouis, MO: Missouri Botanical Garden Press.
Guo, Z. T., Ruddiman, W. F., Hao, Q. Z., Wu, H. B., Qiao, Y. S., Zhu, R. X., et al. (2002). Onset of Asian desertification by $22 \mathrm{Myr}$ ago inferred from loess deposits in China. Nature 416, 159-163. doi: 10.1038/416159a

Hall, T. A. (1999). BioEdit: a userfriendly biological sequence alignment editor and analysis program for Windows 95/98/NT. Nucleic Acids Symp. Ser. 41, 95-98.

Hallinger, M., Manthey, M., and Wilmking, M. (2010). Establishing a missing link: warm summers and winter snow cover promote shrub expansion into alpine tundra in Scandinavia. New. Phytol. 186, 890-899. doi: 10.1111/j.1469-8137.2010.03223.x

Hallinger, M., and Wilmking, M. (2011). No change without a cause - why climate change remains the most plausible reason for shrub growth dynamics in Scandinavia. New. Phytol. 189, 902-908. doi: 10.1111/j.1469-8137.2010.03624.x

Harmon, L. J., Weir, J. T., Brock, C. D., Glor, R. E., and Challenger, W. (2008). GELGER: investigating evolutionary radiations. Bioinformatics 24, 129-131. doi: 10.1093/bioinformatics/btm538

Hu, J. M., Lavin, M., Wojciechowski, M. F., and Sanderson, M. J. (2000). 
Phylogenetic systematics of the tribe Millettieae (Leguminosae) based on chloroplast $\mathrm{trnK} / \mathrm{mat} K$ sequences and its implications for evolutionary patterns in Papilionoideae. Am. J. Bot. 87, 418-430. doi: $10.2307 / 2656638$

Jabbour, F., and Renner, S. S. (2012). A phylogeny of Delphinieae (Ranunculaceae). shows that Aconitum is nested within Delphinium and that Late Miocene transitions to long life cycles in the Himalayas and Southwest China coincide with bursts in diversification. Mol. Phylogenet. Evol. 62, 928-942. doi: 10.1016/j.ympev.2011.12.005

Jacobs, B. F. (2004). Palaeobotanical studies from tropical Africa: relevance to the evolution of forest, woodland and savannah biomes. Phil. Trans. R. Soc. Lond. B Biol. Sci. 359, 1573-1583. doi: 10.1098/rstb.2004.1533

Lantz, T. C., Kokelj, S. V., Gergel, S. E., and Henry, G. H. R. (2009). Relative impacts of disturbance and temperature: persistent changes in microenvironment and vegetation in retrogressive thaw slumps. Glob. Change Biol. 15, 1664-1675. doi: 10.1111/j.1365-2486.2009.01917.x

Larkin, M. A., Blackshields, G., Brown, N. P., Chenna, R., McGettigan, P. A., McWilliam, H., et al. (2007). Clustal W and Clustal X v2.0. Bioinformatics 23, 2947-2948. doi: 10.1093/bioinformatics/btm404

Lavin, M., Eshbaugh, E., Hu, J. M., Mathews, S., and Sharrock, R. A. (1998). Monophyletic subgroups of the tribe Millettieae (Leguminosae) as revealed by phytochrome nucleotide sequence data. Am. J. Bot. 85, 412-433. doi: $10.2307 / 2446334$

Lavin, M., Herendeen, P., and Wojciechowski, M. (2005). Evolutionary rates analysis of Leguminosae implicates a rapid diversification of lineages during the Tertiary. Syst. Biol. 54, 575-594. doi: $10.1080 / 10635150590947131$

Lee, J., and Hymowitz, T. (2001). A molecular phylogenetic study of the subtribe Glycininae (Leguminosae) derived from the chloroplast DNA rps16 intron sequences. Am. J. Bot. 88, 2064-2073. doi: $10.2307 / 3558432$

Lewis, G., Schrire, B., Machinder, B., and Lock, M. (2005). Legumes of the World. Kew: The Royal Botanic Gardens.

Maddison, W. P., and Maddison, D. R. (2009). "Mesquite: a modular system for evolutionary analysis v2.74," in Computer Program and Documentation Distributed by the Author. Available online at: http://mesquiteprojectorg/ mesquite/mesquitehtml.

Magallón, S., and Sanderson, M. J. (2001). Absolute diversification rates in angiosperm clades. Evolution 55, 1762-1780. doi: 10.1111/j.00143820.2001.tb00826.x

Miller, M. A., Pfeiffer, W., and Schwartz, T. (2010). "Creating the CIPRES Science Gateway for inference of large phylogenetic trees," in Proceedings of the Gateway Computing Environments Workshop (GCE), (New Orleans, LA), 1-8. doi: 10.1109/GCE.2010.5676129

Minnich, R. A. (2007). "Climate, Paleoclimate, and Paleovegetation," in Terestrial vegetation of California, 3rd Edn, eds A. G. Barbour, T. Keeler-Wolf, and A. A. Schoenherr (London: University of California Press), 43-70. doi: 10.1525/california/9780520249554.003.0002

Mosbrugger, V. (2005). Cenozoic continental climatic evolution of central Europe. Proc. Natl. Acad. Sci. U.S.A. 102, 14964-14969. doi: 10.1073/pnas.0505267102

Nylander, J. A. A., Olsson, U., Alström, P., and Sanmartín, I. (2008). Accounting for phylogenetic uncertainty in biogeography: a bayesian approach to dispersal-vicariance analysis of the thrushes (Aves: Turdus). Syst. Biol. 57, 257-268. doi: 10.1080/10635150802044003

Pälike, H., Norris, R. D., Herrle, J. O., Wilson, P. A., Coxall, H. K., Lear, C. H., et al. (2006). The heartbeat of the Oligocene climate system. Science 314, 1894-1898. doi: 10.1126/science. 1133822

Paradis, E., Claude, J., and Strimmer, K. (2004). APE: analyses of phylogenetics and evolution in R language. Bioinformatics 20, 289-290. doi: 10.1093/bioinformatics/btg412

Posada, D., and Crandall, K. A. (1998). MODELTEST: testing the model of DNA substitution. Bioinformatics 14, 817-818. doi: 10.1093/bioinformatics/14.9.817

Prothero, D. R. (1994). The late Eocene-Oligocene extinctions. Ann. Rev. Earth Planet Sci. 22, 145-165. doi: 10.1146/annurev.ea. 22.050194.001045

Raup, D. M., and Sepkoski, J. J. (1986). Periodic extinction of families and genera. Science 231, 833-836. doi: 10.1126/science. 11542060

Rejmánek, M., and Richardson, D. M. (2013). Trees and shrubs as invasive alien species - 2013 update of the global database. Divers. Distrib. 19, 1093-1094. doi: 10.1111/ddi.12075
Schluter, D. (2000). The Ecology of Adaptive Radiation. Oxford: Oxford University Press.

Shaver, G. R., Giblin, A. E., Nadelhoffer, K. J., and Rastetter, E. B. (1997) "Plant functional types and ecosystem change in arctic tundra," in Plant Functional Types, eds T. Smith, I. Woodward, and H. Shugart (Cambridge: Cambridge University Press), 153-173.

Sprent, J. I. (2007). Evolving ideas of legume evolution and diversity: a taxonomic perspective on the occurrence of nodulation. New Phytol. 174, 11-25. doi: 10.1111/j.14698137.2007.02015.x

Stefanović, S., Pfeil, B. E., Palmer, J. D., and Doyel, J. J. (2009). Relationships among phaseoloid legumes based on sequences from eight chloroplast regions. Syst. Bot. 34, 115-128. doi: $\quad 10.1600 / 0363644097876$ 02221

Strömberg, C. A. E. (2011). Evolution of grasses and grassland ecosystems. Ann. Rev. Earth Planet Sci. 39, 517-544. doi: 10.1146/annurevearth-040809-152402

Sturm, M., Schimel, J., Michaelson, G., Welker, J. M., Oberbauer, S. F., Liston, G. E., et al. (2005). Winter biological processes could help convert Arctic tundra to shrubland. Bioscience 55, 17-26. doi: 10.1641/0006-3568(2005)055[0017: WBPCHC]2.0.CO;2

Tape, K., Sturm, M., and Racine, C. (2006). The evidence for shrub expansion in Northern Alaska and the Pan-Arctic. Glob. Change Biol. 12, 686-702. doi: 10.1111/j.13652486.2006.01128.x

Tiffney, B. H., and Mazer, S. J. (1995). Angiosperm growth habit dispersal and diversification reconsidered. Evol. Ecol. 9, 93-117. doi: 10.1007/BF01237700

Töpel, M., Antonelli, A., Yesson, C., and Eriksen, B. (2012). Past climate change and plant evolution in western North America: a case study in Rosaceae. PLoS ONE 7:e50358. doi: 10.1371/journal.pone. 0050358

Verdú, M. (2002). Age at maturity and diversification in woody angiosperms. Evolution 56, 1352-1361. doi: 10.1111/j.00143820.2002.tb01449.x

Wade, B. S., and Pälike, H. (2004). Oligocene climate dynamics. Paleoceanography 19, PA2019. doi: 10.1029/2004PA001042

Wang, Q., Manchester, S. R., and Dilcher, D. L. (2010). Fruits and foliage of Pueraria (Leguminosae, Papilionoideae) from the Neogene of Eurasia and their biogeographic implications.
Am. J. Bot. 97, 1982-1998. doi: 10.3732/ajb.1000167

Wojciechowski, M. F., Lavin, M., and Sanderson, M. J. (2004). A phylogeny of legumes (Leguminosae) based on analysis of the plastid $m a t K$ gene resolves many wellsupported subclades within the family. Am. J. Bot. 91, 1846-1862. doi: 10.3732/ajb.91.11.1846

Yoder, J. B., Clancey, E., Des Roches, S., Eastman, J. M., Gentry, L., Godsoe, W., et al. (2010). Ecological opportunity and the origin of adaptive radiations. J. Evol. Biol. 23, 1581-1596. doi: 10.1111/j.1420-9101.2010.02029.x

Yu, Y., Harris, A. J., and He, X. (2011). RASP (Reconstruct Ancestral State in Phylogenies) 1.1. Available online at: http://mnh.scu.edu. $\mathrm{cn} / \mathrm{soft} / \mathrm{blog} / \mathrm{RASP}$

Zachos, J., Pagani, M., Sloan, L., Thomas, E., and Billups, K. (2001). Trends rhythms and aberrations in global climate $65 \mathrm{Ma}$ to present. Science 292, 686-693. doi: 10.1126/science. 1059412

Zhang, P., Chen, Y. Q., Zhou, H., Liu, Y. F., Wang, X. L., Papenfuss, T. J., et al. (2006). Phylogeny, evolution, and biogeography of Asiatic Salamanders (Hynobiidae). Proc. Natl. Acad. Sci. U.S.A. 103, 7360-7365. doi: 10.1073/pnas.0602325103

Conflict of Interest Statement: The authors declare that the research was conducted in the absence of any commercial or financial relationships that could be construed as a potential conflict of interest.

Received: 26 July 2013; accepted: 11 September 2013; published online: 09 October 2013.

Citation: Li H, Wang W, Lin L, Zhu $X$, Li J, Zhu X and Chen $Z$ (2013) Diversification of the phaseoloid legumes: effects of climate change, range expansion and habit shift. Front. Plant Sci. 4:386. doi: 10.3389/fpls.2013.00386

This article was submitted to Plant Evolution and Development, a section of the journal Frontiers in Plant Science. Copyright $\odot 2013 \mathrm{Li}$, Wang, Lin, Zhu, Li, Zhu and Chen. This is an open-access article distributed under the terms of the Creative Commons Attribution License (CC BY). The use, distribution or reproduction in other forums is permitted, provided the original author(s) or licensor are credited and that the original publication in this journal is cited, in accordance with accepted academic practice. No use, distribution or reproduction is permitted which does not comply with these terms. 